\title{
Morphodynamic modelling for a tidal inlet in the Wadden Sea
}

\author{
Z.B. Wang ${ }^{a}$, T. Louters ${ }^{b}$ and H.J. de Vriend ${ }^{c}$ \\ ${ }^{a}$ Delft Hydraulics, and Delft University of Technology, Faculty of Civil Engineering, P.O. Box 177, 2600 MH Delft, \\ The Netherlands \\ ${ }^{b}$ Rijkswaterstaat, National Institute for Coastal and Marine Management (RIKZ), P.O. Box 20907, \\ 2500 EX Den Haag, The Netherlands \\ ${ }^{\complement}$ University of Twente, School of Management Studies, Department of Civil Engineering and Management, P.O. Box 217, \\ 7500 AE Enschede, The Netherlands
}

Received 14 February 1994; revision accepted 5 January 1995

\begin{abstract}
A dynamic model for morphological development in a tidal inlet, "Het Friesche Zeegat", in the Wadden Sea along the northern coast of the Netherlands, is set up to obtain a better understanding of the behaviour of the morphological system around tidal inlets. The model is based on DELMOR, a program package for morphological changes, developed at Delft Hydraulics. Computations of the flow, the sediment transport, the initial bed level change rate as well as long-term morphological development have been carried out. The model has proven to be a useful research tool, even though it does not yet reproduce reality in detail.
\end{abstract}

\section{Introduction}

The evolution of the Dutch coast is subject of an integrated research project, COASTAL GENESIS. As far as the morphological development of tidal inlets is concerned, the project is aiming at a better understanding of the physical processes and the mechanisms underlying the morphological evolution.

For this purpose a morphodynamic study of "Het Friesche Zeegat", a tidal inlet system in the Wadden Sea (Fig. 1), is made, as a pilot application of a generally applicable morphodynamic modelling system. Since 1969, this tidal inlet system, with an area of about $450 \mathrm{~km}^{2}$, has undergone significant morphological changes due to the reclamation of a large part of it, the Lauwerszee. As a consequence the in- and outgoing tidal volume has been reduced by about $34 \%$.

The response of this tidal inlet system to the closure of the Lauwerszee is well documented. The deeper parts of the outer delta are eroding, large bars are forming, the tidal channels are shoaling and the eastern watershed is shifting eastward.

A description of the model and the first results from the model have been reported by Wang et al. (1991). This paper focuses on further analysis of the results of the model computations, after a brief description of the set-up of the model.

\section{Mathematical model}

The morphological evolution around a tidal inlet is the result of a very complicated interaction of tide, wind, waves and sediment. In order not to have all complexity at the same time, the present model focuses on areas where the tide is the principal transport agent. This means that it cannot be expected to be valid for the outer delta 


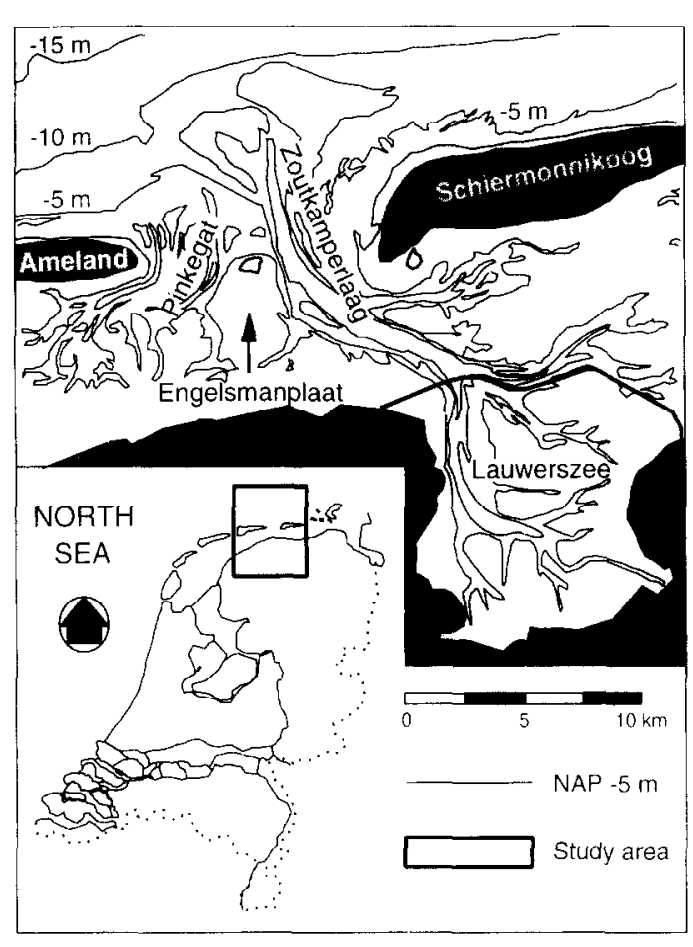

Fig. 1. Study area: "Het Friesche Zeegat".

and the barrier island coast. Outside these areas, it is attempted to reduce the model to its essence via the following simplifications:

- density currents are not taken into account,

- the sediment is non-cohesive, and

- the sediment consists of one single fraction.

The influence of wave action is taken into account via a rough estimate of the wave height, which is put into a bed shear stress enhancement formula. Clearly, this is too crude a model for areas where waves play an important role.

The model is based on DELMOR, a program package to simulate morphological evolutions, which was developed by Delft Hydraulics. The program consists of the following basic modules:

- A quasi-3D current module, based upon the TRISULA-model (Stelling and Leendertse, 1992) which solves the shallow water equations. The vertical structure of the flow is determined afterwards. The downstream velocity profile is assumed logarithmic. In the cross-stream direction the curvature-induced secondary flow and the
Coriolis effect are taken into account via the model of Kalkwijk and Booij (1986).

- A quasi-3D sediment transport module describing bed load and suspended load transport due to current and waves. For the time being the sediment transport due to waves can only be incorporated by modifying the bed shear stress.

The sediment transport is divided into a bed load and a suspended load part. The bed load transport is calculated with a transport formula, e.g. Van Rijn's (1984). Further the down-slope gravitational effect on the transport is taken into account. The suspended load transport is modelled by a quasi-3D approach based on an asymptotic solution of the 3D advection-diffusion equation for the sediment concentration (Galappatti and Vreugdenhil, 1985; Wang and Ribberink, 1986; Wang, 1992a,b).

- A sediment balance module which determines the sedimentation and erosion rate and the new bed level from the sediment balance.

The modules are put in line as indicated in Fig. 2, with a "quasi-steady" morphodynamic time-stepping mechanism, i.e. during the flow computation the bed level is assumed to remain invariant and during the computation of the bed level (with a time step of a number of tidal periods) the flow and sediment transport are assumed invariant to the bed level changes (cf. De Vries, 1993). More complicated procedures for morphological computations in tidal regions have been studied by Hauguel (1978) and De Vriend et al. (1993). Because experience with these procedures is still

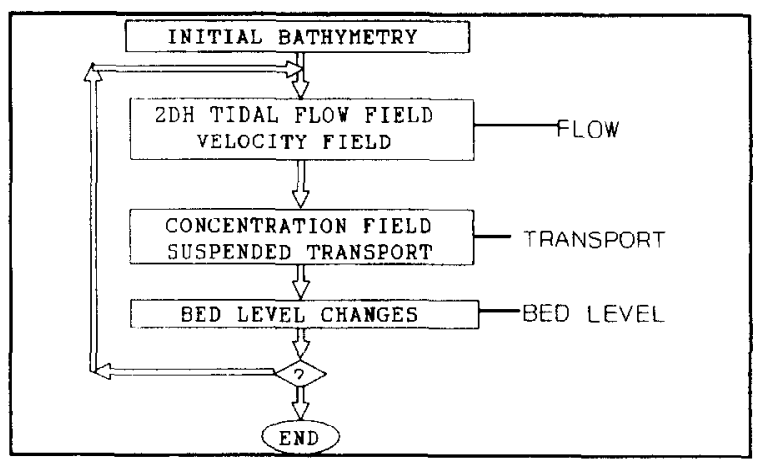

Fig. 2. The computational procedure. 
limited, this study will stick to the straightforward procedure shown in Fig. 2.

Further details on this model and the relevant mathematical physics are given by Wang et al. (1991).

\section{Schematization}

Fig. 1 shows a map of the "Friesche Zeegat". The basin behind this inlet is roughly rectangular and covers an area of about $195 \mathrm{~km}^{2}$. The gorge between the two barrier islands has a width of about $10 \mathrm{~km}$. Both barrier islands are approximately parallel to the mainland boundary. The western island has a width of about $2 \mathrm{~km}$, the eastern island is about $3 \mathrm{~km}$ wide. The geometrical schematisation is such that the main features of the system are represented, whereas details are determined by the shape of the computational grid rather than by the actual geometry. The longshore extent of the sea area should be about $30 \mathrm{~km}$ and the cross-shore extent should be some $10 \mathrm{~km}$, in order to let the model encompass the entire outer delta without being affected by the adjacent inlets.

A curvilinear grid is used in the model (Fig. 3). As can be seen from this figure the shape of the Lauwerszee in the model is clearly different from reality. The main characteristics, such as the area of the basin at different water levels and the cross section at the connection with the present basin are about the same as in nature. Such a schematisation is allowed because the morphology of the Lauwerszee itself is not the subject of this study. The minimum grid size in the gorge area is about $200 \mathrm{~m}$ and the maximum grid size in the open sea area is about $3000 \mathrm{~m}$. The time step for the flow computation is $60 \mathrm{~s}$ whereas the time step for the morphological computations varies from case to case, and some times even within a case.

\section{Results and analysis}

\subsection{Influence of tidal constituents}

At the open sea boundary the water level is prescribed as a boundary condition for the hydro- dynamic module. The required water level data is obtained from oostwAD, a $2 \mathrm{DH}$ fixed-bed tidal flow model developed by Rijkswaterstaat, which covers a large area of the Wadden Sea and the North Sea. Analysis of the water level at the boundary shows that the semi-diurnal constituent is dominant, but that others are also present. In order to examine which constituents are important and in what detail their variation along the boundary should be taken into account, a number of computations has been carried out with different combinations of the constituents in different degrees of detail. Analysis of the resulting residual sediment transport fields leads to the following conclusions: (1) the boundary condition can be composed of the semi-diurnal and the quarterdiurnal tides; (2) the amplitude of either tidal constituent can be set constant along the boundary; (3) the variation of the phases can be described by specifying the phases at either ends of the boundary and interpolating linearly.

On the basis of a 5 th power transport formula and some other crude assumptions, it can be shown that the tidal residual transport through the gorge should be proportional to $\left(a^{4} b+6 a^{2} b^{3}\right) \sin \phi$, in which $a$ and $b$ are the amplitude of the semidiurnal and quarter-diurnal tides, respectively, and $\phi$ is the phase lag between the two. The results of the model computations correspond well with this crude formula. A more sophisticated analytical expression for the tidally averaged sediment transport is derived by Van de Kreeke and Robaczewska (1993).

The tide-induced residual sediment transport field is shown in Fig. 4.

\subsection{Influence of waves}

Sea waves can be a major transport agent, because they stir sediment via the orbital motion, and they can give rise to net currents and residual transport (e.g. littoral drift, wave-borne transport). The present model only include a crude approximation of the stirring effect, via a wave-induced enhancement of the bed shear stress (Bijker, 1971).

To examine the influence of waves, the simulation which led to Fig. 4 was repeated including a strongly simplified wave field: waves exist only 


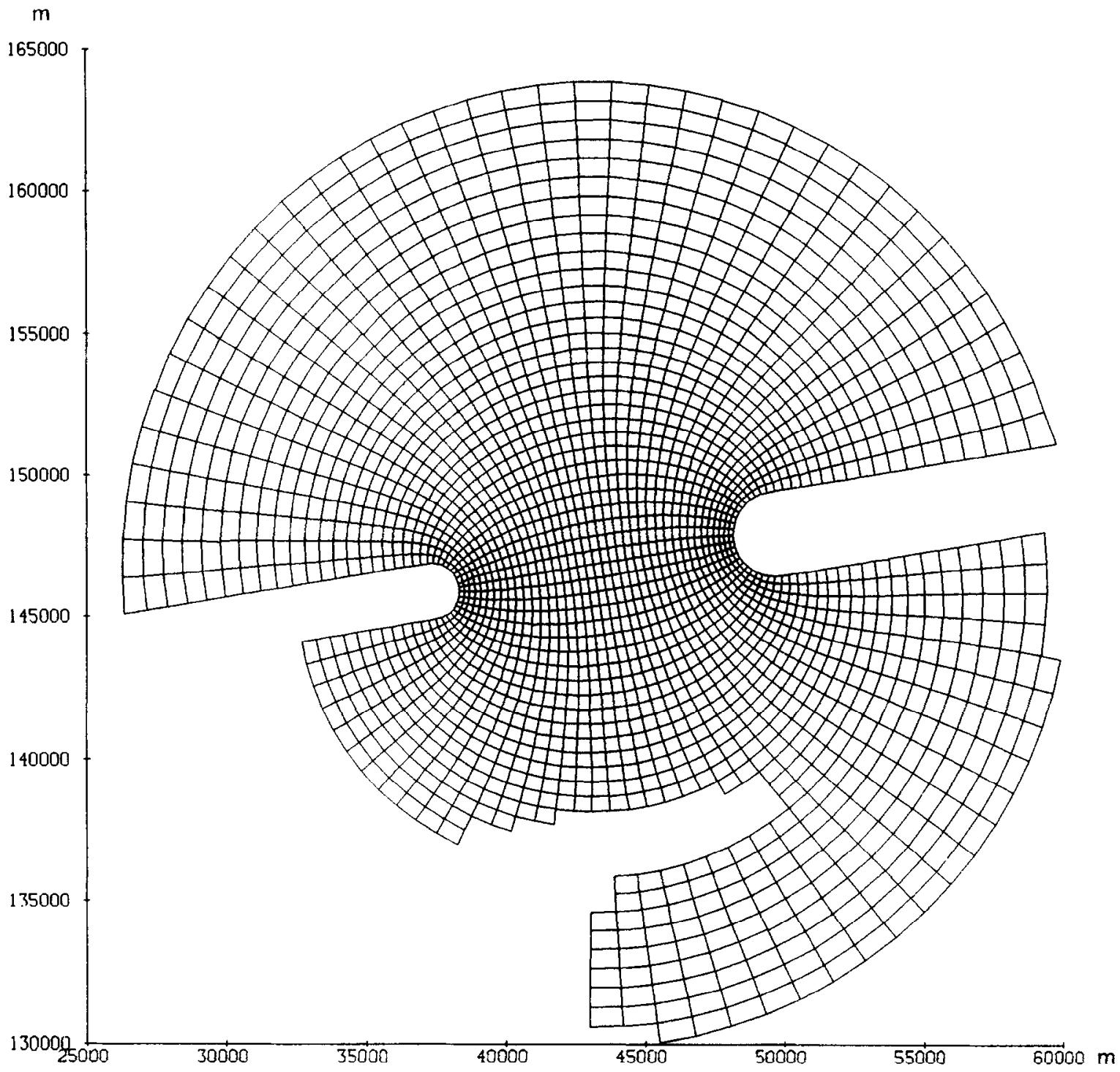

Fig. 3. Computational grid.

outside the inlet and have a constant height of 1 $\mathrm{m}$ and a period of $5 \mathrm{~s}$. Wave decay by breaking is taken into account by setting the maximum wave height at a fraction of the water depth. In reality the influence of waves will be felt mainly at the outer delta, where most of their energy is dissipated. Even in a wide open inlet like the "Friesche Zeegat", wave penetration from the sea into the basin is limited (Steijn and Hartsuiker, 1992).

The computed residual sediment transport is shown in Fig. 5. Outside the inlet, the influence of the waves on the sediment transport appears to be quite strong: the sediment transport rates are much larger than in Fig. 4. Inside the inlet, where no waves are present, the difference between the results from the two simulations is not significant. Apparently, the wave influence on the transport is restricted to the outer delta and does not penetrate into the basin. Whether this is also the case for the longer-term morphological evolution is not clear. Most of the empirical relationships which describe the equilibrium state of the principal 


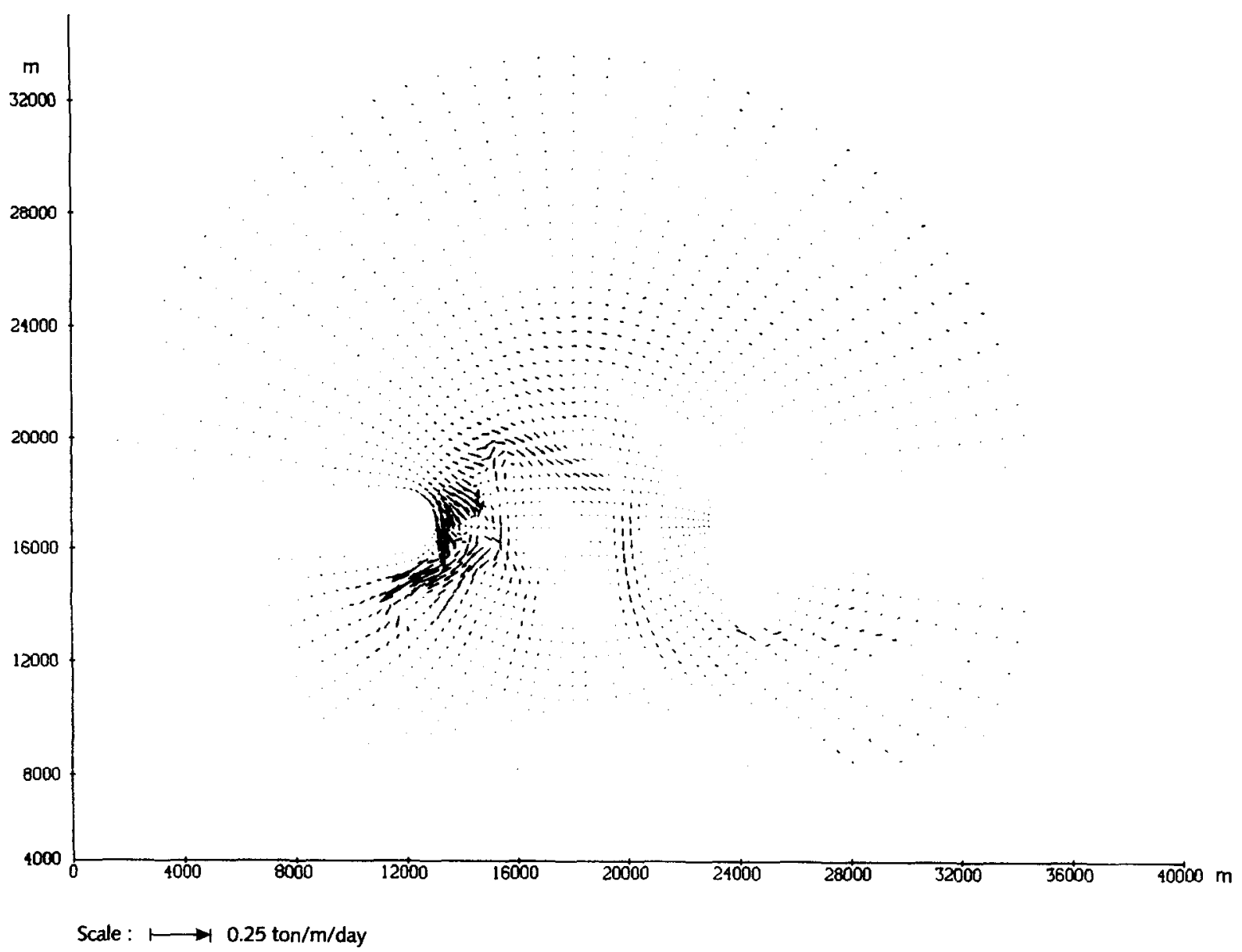

Fig. 4. Residual sediment transport due to tidal flow with closure.

morphological units in terms of total volumes (even of the outer delta) do not include wave influence, whereas they appear to hold good for the Wadden Sea inlets (Gerritsen, 1990). This seems to indicate that even a model which disregards the wave influence can describe the morphological behaviour at this high aggregation level, at least inside the basin.

\subsection{Development from smoothed bed}

A number of long-term simulations have been carried out with different initial bathymetries. The results of two such compulations have already been reported by Wang et al. (1991). Here the result of another simulation is presented (Fig. 6).
The initial bathymetry is obtained by smoothing the realistic bathymetry in the lateral direction of the channels. This ensures that the total amount of sediment in the whole area remains the same. In these computations only the tide-driven (semidiurnal + quarter-diurnal) transport is considered. In total 100 morphological time stcps of 50 days have been simulated. Note that the net sediment transport rate is probably smaller than in reality. As a consequence, the morphological time scale is probably too large, and the time span covered is larger than in reality.

Fig. 6 shows the bathymetry at the end of the simulation. Clearly the model does not restore the original bathymetry in detail. Yet a number of interesting features can be observed. In the 


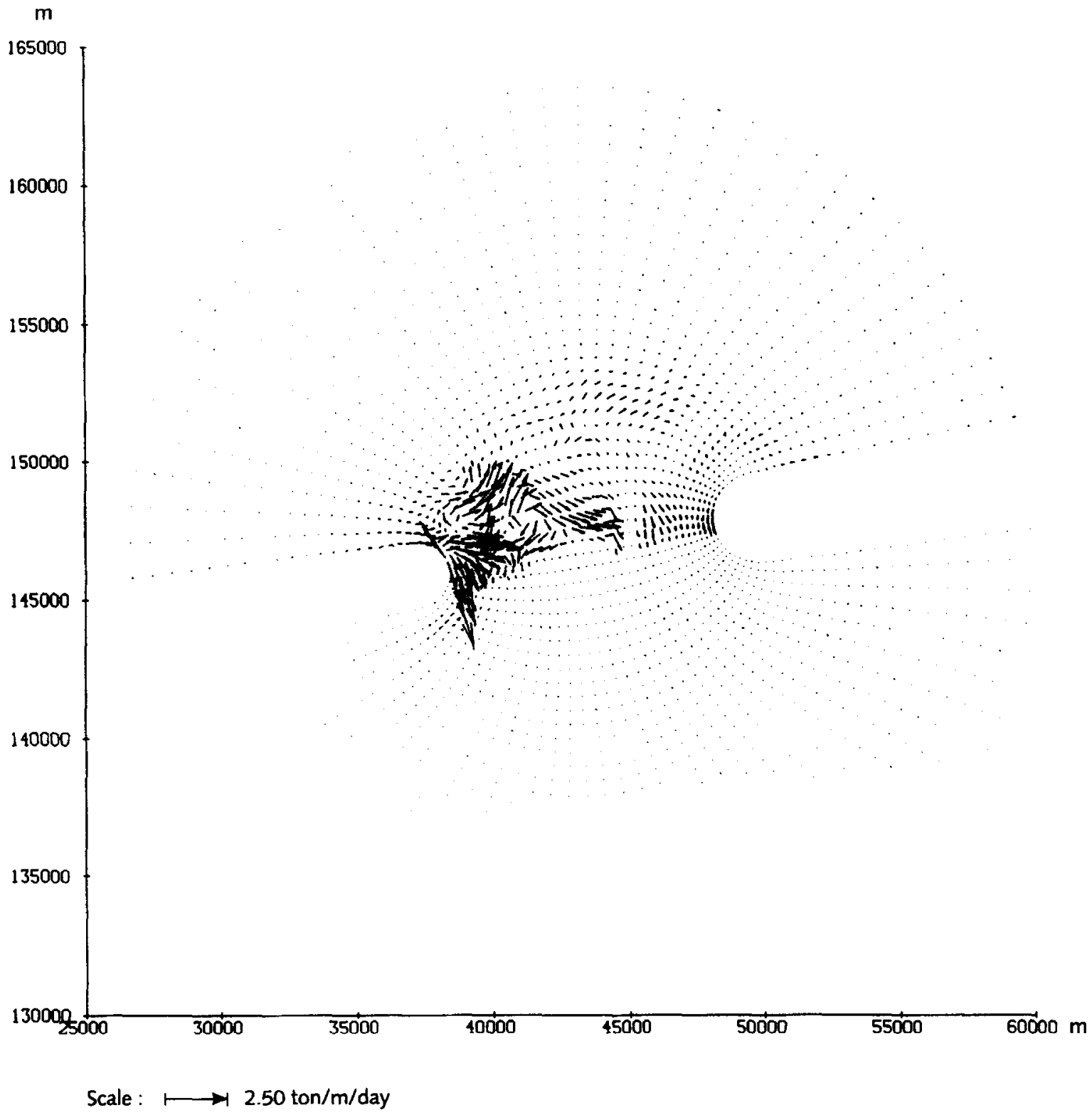

Fig. 5. Residual sediment transport due to tide and waves.

Pinkegat area, where the morphological changes are relatively fast, a channel structure develops which is similar to the one in reality. As the model appears to describe the dynamic behaviour of the Pinkegat (channel migration and formation), it should also contain the explanation of this behaviour. However, this requires further study and experimentation with the model. In the
Zoutkamperlaag area the development is much slower. The channel slightly changes its orientation and the it extends somewhat further into the basin. In the outer delta area of the Zoutkamperlaag two shallow sandbanks develop with a flood channel in between, much like in reality.

The difference in morphological time scales between the Pinkegat and the Zoutkamperlaag 


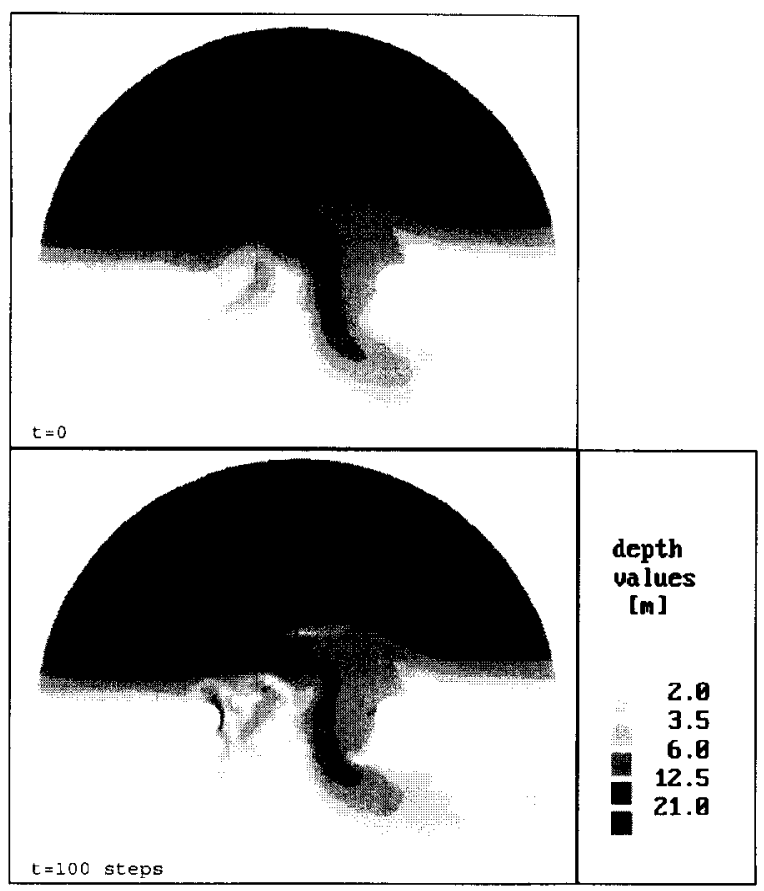

Fig. 6. Morphological evolution from a smoothed initial bathymetry (unit: $m$ water depth below datum).

areas agrees with observations in the nature. It poses a serious problem to the numerical model, as the time step is determined by the smallest time scale in the system. As a consequence, much computational effort is required in order to simulate the development of the Zoutkamperlaag area in the presence of the Pinkegat.

\subsection{Short-term response to the closure}

Since the model cannot be expected to reproduce every detail of the real bathymetry, the response of the system to the Lauwerszee closure is investigated by comparing the model results for the situation without and with closure. First the shortterm response is investigated by examining the hydrodynamics, the sediment transport and the initial bed level change.

As an example Fig. 7 shows the computed water level, flow velocity and sediment concentration at a station in the deep part in the gorge without and with closure. The water levels exhibit a phase lag and an increase of the tidal amplitude with closure.
The flow velocity decreases considerably due to the closure, as was to be expected because of the reduced basin area. There is also a considerable phase difference between the computed flow velocity distributions, but, more importantly, the phase difference at low water is larger than that at high water. This has a significant impact on the tidal asymmetry: at this particular location the tidal asymmetry is even reversed, from ebb-dominant to flood-dominant. The net sediment transport through the gorge with closure is directed landwards (Fig. 4), which agrecs with the observation that the tidal basin has trapped large amounts of sediment since the closure (Biegel, 1991). It also agrees with the hypothesis of Van Dongeren and De Vriend (1994) that the tidal asymmetry is dependent on the relative area of the inter tidal flats (the Lauwerszee had a relatively higher percentage of flats).

\subsection{Long-term response to the closure}

Both computations described above have been continued for 180 morphological time steps in order to investigate the long-term response. In order to avoid the time scale problem mentioned earlier, the bathymetry in the Pinkegat area was kept fixed during the long-term simulations.

For the situation without closure the morphological time step is 6 days for the first 30 steps and 18 days for the other 150 steps. For the situation with closure the time steps are 10 times larger because the magnitude of the sediment transport is much smaller and hence the morphological time scale is much larger. The time step in the first part of the simulations is smaller in order to cope with fast initial changes due to e.g. disturbances in the schematised initial bathymetry.

The computed bathymetry without closure is shown in Fig. 8. The initial bathymetry of this computation is measured shortly after the closure of the Lauwerszee and it is assumed to approximate the equilibrium state before closure. The computational results predict a further evolution of this bathymetry, so according to the model it is not in equilibrium. For the outer delta area this is not strange, because channels have been observed to be continuously migrating there. The total 

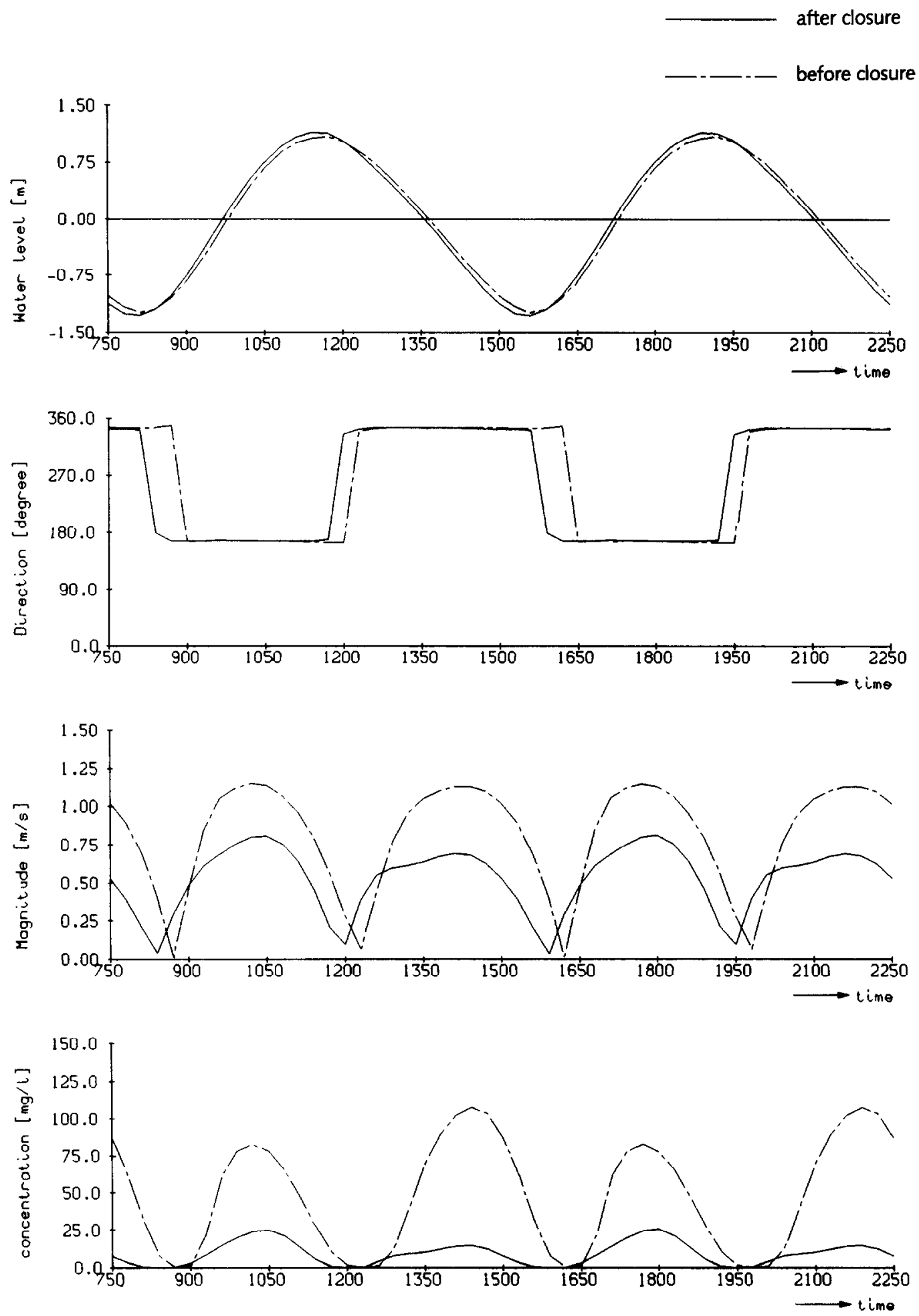

Fig. 7. Water level, flow velocity and sediment concentration without and with closure of Lauwerszee. 


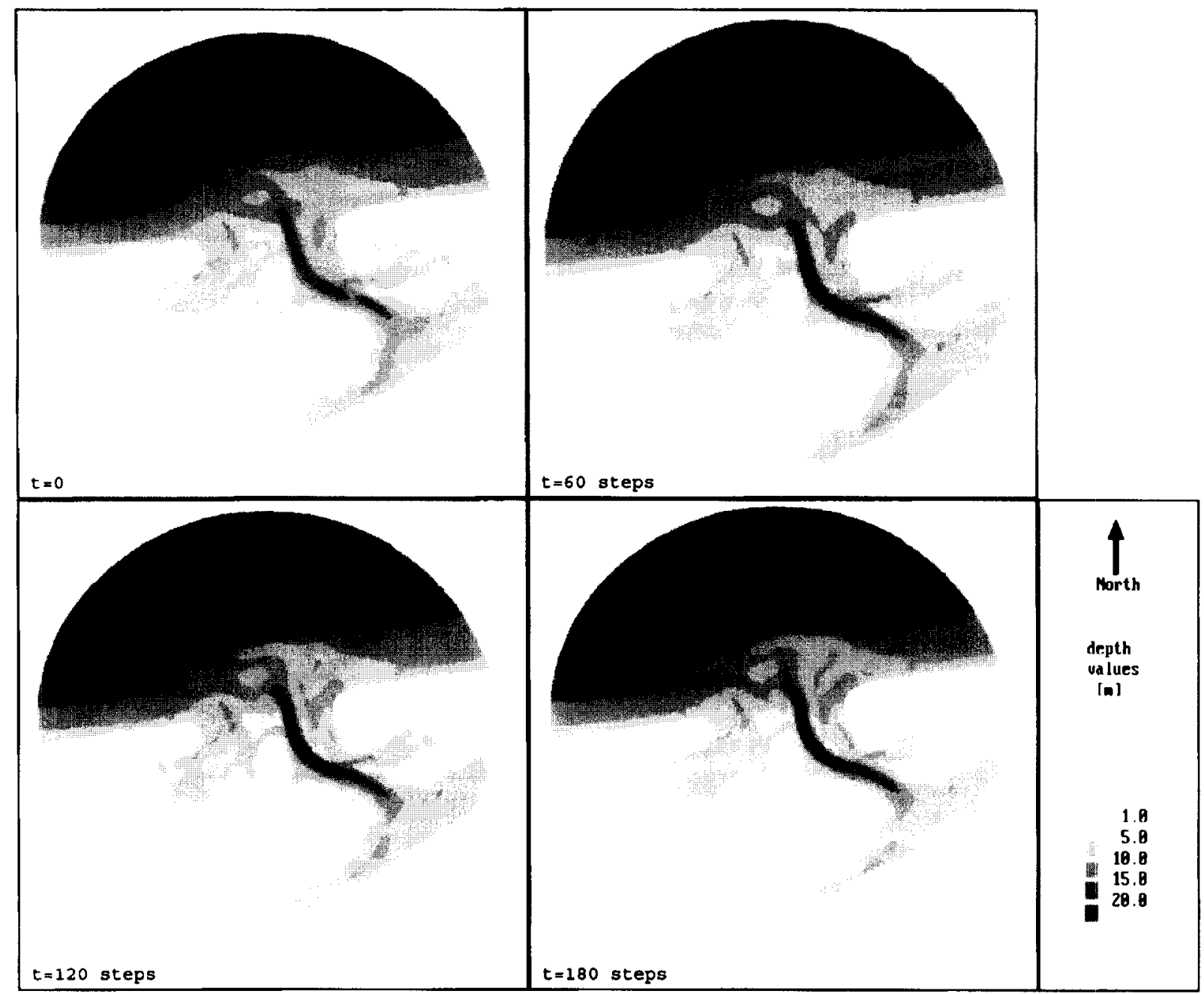

Fig. 8. Development of bathymetry without closure.

volume of the basin does not change much during the simulation, but local changes do occur: the main channel becomes consistently narrower and deeper as the computation proceeds. Clearly the model does not reproduce the natural equilibrium bathymetry in detail. A possible explanation is that the model does not include waves which are generated inside the basin. Such waves can have an important erosive effect on the channel banks and give rise to smaller equilibrium bank slopes (De Vriend et al., 1989).

Fig. 9 shows the results of the simulation for the situation with closure. The initial bathymetry and the boundary conditions are all the same as in the case without closure. The results of this hindcast can be compared with the measurement since the closure. The total bed level change according to the two computations is shown in Fig. 10, together with the measured changes between 1970 and 1987. The computational results show that the closure causes substantial morphological changes. The tidal basin is trapping large amounts of sediment, which is in agreement with the measurements. In contrast with the simulation for the case without closure most parts of the main channel are shoaling, especially further inside the basin. At the outer delta area the agreement between computed and measured data is much 


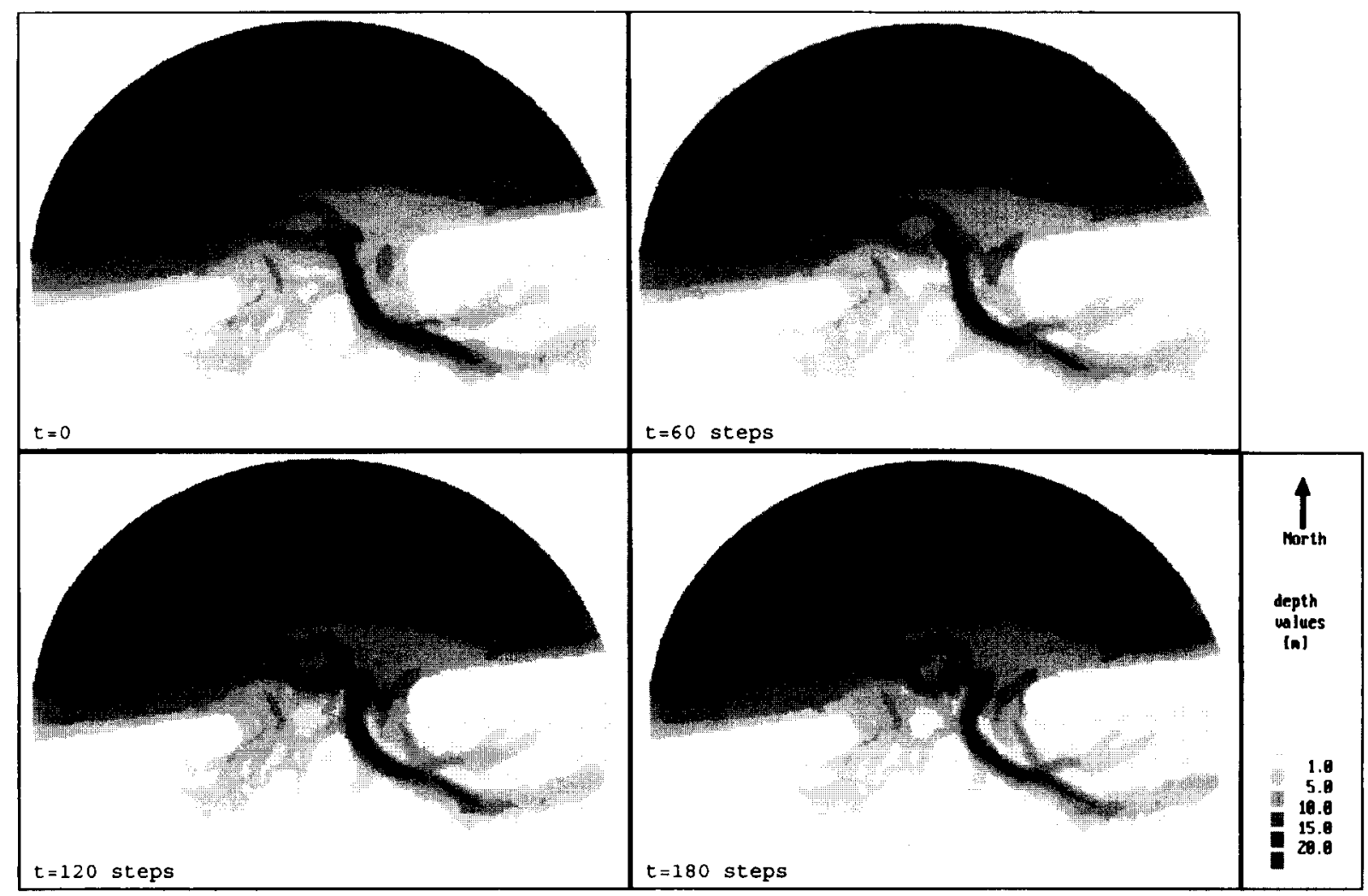

Fig. 9. Development of bathymetry with closure.

worse. The outer delta is losing sediment, which is in agreement with the measurements but the development of the shape of the delta is totally different from reality. This must probably be attributed to the fact that the wave influence is not taken into account.

A comparison between the evolutions of the tidal basin volume shows that the morphological time scale in the model is about 3 times as large as in reality. This means that the real time interval simulated in this computation is 26 years rather than 80 years. The most likely explanation is the lack of wave influence in the model, due to which the transport rate are much smaller than in reality.

Apparently, the morphological evolution inside the basin is mainly driven by the tide. Here the influences of waves is restricted to details, e.g. shape of channels. In the outer delta area waves are more important. Here the computational results only make sense if the highest aggregation level (i.e the total volume of the delta) is considered. As stated before, neglecting the wave influence also leads to a much too large morphological time scale. This shortcoming can easily be taken into account in the interpretation of the model results.

Furthermore, the computational results suggest that the influence of the closure is restricted to the basin-inlet-delta system itself: the influence of the adjacent coast is small. It has to be noted, however, that the interaction with the adjacent coast will probably proceed through wave-induced processes which are not included in the model (cf. De Vriend et al., 1994).

\section{Conclusion}

A pilot morphodynamic model has been set up for "Het Friesche Zeegat", a tidal inlet in the 


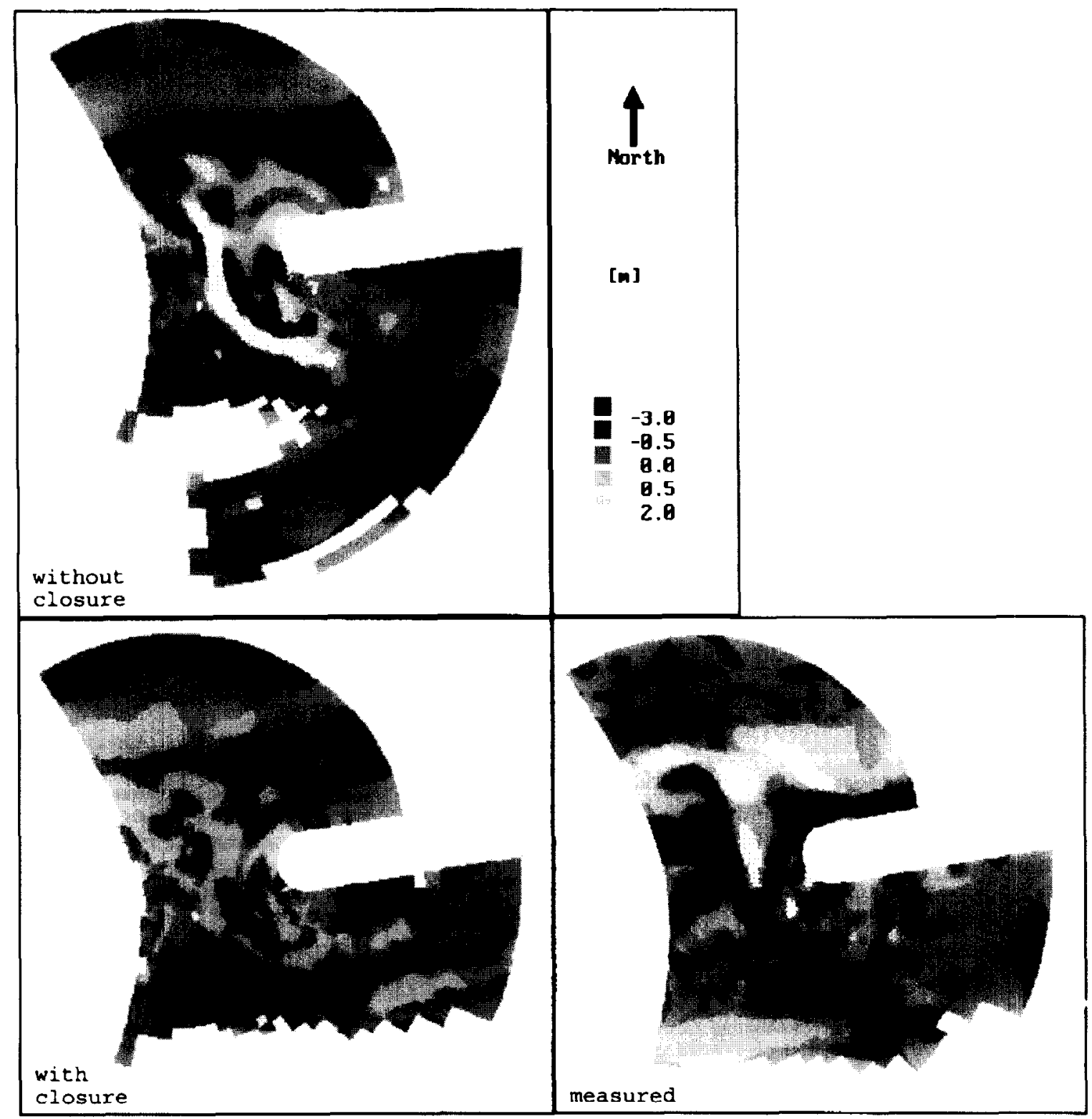

Fig. 10. Total bed level change (top left: without closure; bottom left: with closure).

Wadden Sea. In its present form the model does not describe the natural bathymetry in every detail, but it does reproduce some of the overall features of the system's morphological behaviour, especially in the areas which are sheltered from waves. The model has proven to be a useful tool to investigate the relative importance of the physical processes in the morphological system. It is able to simulate to a certain extent the effect of the closure of a part of the tidal basin.

The model concept is to a large extent generic, in that it is applicable without significant change to other inlets and other types of human interference. It must be doubted, however, whether the model in its present form is able to reproduce the natural evolution to an equilibrium state in more 
detail than the overall volumes of the principal elements (delta, basin, gorge, channels).

The model needs further improvement to become a predictive tool. The following shortcomings of the model should be considered:

- Wave influence: short waves have a significant influence on the sediment transport in the outer delta region. Not only the stirring effect but also the wave driven flow should be included in the model (Steijn and Hartsuiker, 1992).

Sediment sorting: the sediment mixture clearly differs from area to area, whereas the model considers only a single sediment fraction.

- Model boundary: the computational domain is fixed, which means that the movement of the watershed cannot be reproduced.

- Different time scales: in the long-term simulations starting from the real bathymetry, the bed in the Pinkegat area had to be fixed in order to avoid time-scale problems. The influence on the computational results should be assessed. If necessary, a technique to cope with strongly different time scales has to be developed.

\section{Acknowledgement}

The study reported here was carried out within the framework of the COASTAL GENESIS project, which is financed by National Institute for Coastal and Marine Management (RIKZ), Ministry of Public Works of the Netherlands. The authors would like to express their appreciation for the fruitful discussions with the members of the Working Group "Interrupted Coast" of this project.

\section{References}

Biegel, E.J., 1991. The evolution of the ebb-tidal delta and the tidal basin of the Friesche Zeegat in relation to the closure of the Lauwerszee. Univ. Utrecht, Inst. Phys. Geogr, Geopro-rep. (In Dutch.)

Bijker, E.W., 1971. Longshore transport computations. J. Waterways, Harbours Coastal Eng. Div., 97(WW4): $687-701$.
De Vriend, H.J., Louters, T., Berben, F. and Steijn, R.C., 1989. Hybrid prediction of a sandy shoal in a mesotidal estuary. In: R.A. Falconer et al. (Editors), Hydraulic and Environmental Modelling of Coastal, Estuarine and River Waters. Gower Technical, Aldershot, pp. 145-156.

De Vriend, H.J., Capobianco, M., Chesher, T., De Swart, H.E., Latteux, B. and Stive, M.J.F., 1993. Approaches to long-term modelling of coastal morphology: a review. Coastal Eng., 21(1/3): 225269.

De Vriend, H.J., Bakker, W.T. and Bilse, D.P., 1994. A morphological behaviour model for the outer delta of mixedenergy tidal inlets. Coastal Eng., 23(3/4): 305-327.

De Vries, M., 1993. Use of Models for River Problems. UNESCO Publishing, Stud. Rep. Hydrol., 51.

Galapatti, R. and Vreugdenhil, C.B., 1985. A depth-integrated model for suspended sediment transport. J. Hydraul. Res., 23(4): 359-377.

Gerritsen, F., 1990. Morphological stability of inlets and channels of the Western Wadden Sea. Rijkswaterstaat, Rep., GWAO-90-019.

Hauguel, A., 1978. Utilisation des modèles mathématiques pour l'étude du transport solide sous l'action des courants de Marée. Rep., E42/78.41, EDF, Direction Etudes Recherches.

Kalkwijk, J.P.Th. and Booij, R., 1986. Adaptation of secondary flow in nearly horizontal flow. J. Hydraul. Res., 24( 1): 19-37.

Steijn, R.C. and Hartsuiker, G., 1992. Morphodynamic response of a tidal inlet after a reduction in basin area. Delft Hydraulics, Rep., H840.40.

Stelling, G.S. and Leendertse, I.I., 1992. Approximation of convective processes by cyclic ADI methods, In: M.L. Spaulding et al. (Editors), Proc. Estuarine and Coastal Modelling. (Tampa, FL.) ASCE, New York, pp. 771-782.

Van de Kreeke, J. and Robaczewska, K., 1993. Tide-induced residual transport of coarse sediment; Application to the Ems estuary. Neth. J. Sea Res., 31(3): 209-220.

Van Dongeren, A.R. and De Vriend, H.J., 1994. A model of morphological behaviour of tidal basins. Coastal Eng., 22(3/4): $287-310$.

Van Rijn, L.C., 1984. Sediment transport, Part I: Bed load transport. J. Hydraul. Eng., ASCE, 110(HY10): 1431-1456.

Wang, Z.B., 1992a. Theoretical analysis on depth-integrated modelling of suspended sediment transport. J. Hydraul. Res., 30(3): 403-421.

Wang, Z.B., 1992b. Some considerations on mathematical modelling of morphological processes in tidal regions. In: D. Prandle (Editor), Dynamics and Exchanges in Estuaries and the Coastal Zone. Am. Geophys. Union, Washington, D.C.

Wang, Z.B. and Ribberink, R.J., 1986. The validity of a depthintegrated model for suspended sediment transport. J. Hydraul. Res., 25(1): 53-67.

Wang, Z.B., De Vriend, H.J. and Louters, T., 1991. A morphodynamic model for a tidal inlet. In: A.S. Arcilla et al. (Editors), Computer Modelling in Ocean Engineering '91. Balkema, Kotterdam, pp. 235-245. 